\title{
ANALISIS DEBIT PADA DAS AIR DINGIN MENGGUNAKAN MODEL SWAT
}

\author{
Nika Rahma Yanti ${ }^{1}$, Rusnam ${ }^{2}$, Eri Gas Ekaputra ${ }^{2}$ \\ ${ }^{1}$ Mahasiswa Fakultas Teknologi Pertanian, Kampus Limau Manis-Padang 25163 \\ ${ }^{2}$ Dosen Fakultas Teknologi Pertanian, Kampus Limau Manis-Padang 25163 \\ Fakultas Teknologi Pertanian, Jurusan Pascasarjana TEP \\ Email: nikary43@gmail.com
}

\begin{abstract}
ABSTRAK
Perubahan penggunaan lahan dari lahan bervegetasi ke non vegetasi mengakibatkan besarnya limpasan (run off) sehingga debit menjadi meningkat terutama pada musim hujan. Penelitian ini dilakukan untuk menganalisis debit pada DAS Air Dingin menggunakan model SWAT dan apakah model SWAT dapat diterapkan dalam mempresentasikan debit pada DAS Air Dingin. Model SWAT memerlukan data iklim, peta dan data tanah, curah hujan, kelerengan dan peta penggunaan lahan. Adapun tahapan yang dilakukan yaitu penyiapan data dan peta, deliniasi DAS, pembentukan HRU, simulasi visualisasi, kalibrasi, dan simulasi dengan model SWAT terkalibrasi. Debit DAS Air Dingin berkisar antara $3-30 \mathrm{~m}^{3} / \mathrm{s}$. Setelah dilakukan kalibrasi model SWAT dapat mempresentasikan keadaan hidrologi DAS Air Dingin dengan $\mathrm{R}^{2}$ 0,76 dan NS 0,64 sehingga model SWAT yang dijalankan dapat dikategorikan memuaskan.
\end{abstract}

Kata Kunci - DAS Air Dingin; Debit; SWAT

\section{PENDAHULUAN}

Pertambahan jumlah penduduk mengalami peningkatan dari waktu ke waktu merupakan hal yang patut diperhatikan. Bertambahnya jumlah penduduk mengakibatkan kebutuhan untuk tempat tinggal, industri, perkantoran dan sarana pendukung lainnya yang memberikan pertumbuhan signifikan terhadap pembangunan ekonomi. Pembangunan ekonomi akan memberikan dampak baik terhadap kuantitas sektor industri dan kegiatan ini akan memberikan dampak buruk terhadap kualitas lingkungan.

Penurunan kualitas lingkungan akan memberikan dampak terhadap kinerja sistem hidrologi pada sebuah daerah aliran sungai (DAS) pada suatu wilayah. Terlihat dari seringnya terjadi banjir, longsor, kekeringan, dan bencana alam lainnya yang terjadi belakangan ini. Hal ini tidak terlepas dari kemampuan lahan dalam menampung, menyimpan dan mengalirkan air dalam suatu kawasan.

Perubahan penggunaan lahan merupakan salah satu penyebab banjir, karena perubahan penggunaan lahan mengakibatkan debit puncak naik dari 5 sampai 35 kali di Daerah Aliran Sungai (DAS). Hal ini disebabkan karena tidak ada yang menahan aliran air permukaan (run off) sehingga aliran air permukaan menjadi besar (Kodoatie, 2008). Kegiatan yang bersifat merubah tipe maupun jenis penggunaan lahan dapat memperbesar atau memperkecil hasil air (water yield) (Asdak, 2010).

DAS Air Dingin terletak pada kecamatan Koto Tangah Kota Padang, sungai ini berhulu pada sekitar Bukit Barisan antara Kabupaten Solok dengan Kota Padang, dan bermuara di samudra hindia. Terjadinya perubahan penggunaan lahan akibat peningkatan jumlah penduduk menyebabkan besarnya aliran permukaan pada saat turunnya hujan. Terlihat dari banjir yang terjadi maret 2016 lalu, banjir melanda kota Padang dan yang paling parah terjadi pada kecamatan Koto Tangah. (Padang Ekspres, 2016).

Berbagai Negara termasuk Indonesia mengalami kendala dalam melakukan perancangan model. Kendala yang dihadapi berupa kurangnya dana dan tenaga yang berpengalaman serta data yang dibutuhkan tidak sepenuhnya ada. Model pengelolaan DAS dapat dilakukan dengan berbagai cara salah satunya adalah dengan menggunakan Geographic Information System (GIS). Salah satu software berbasis GIS yang dapat digunakan untuk menganalisis kondisi hidrologi yaitu SWAT (Soil and Water Assesment Tools). Aplikasi SWAT terhubung dengan Sistem Informasi Geografis (GIS). SWAT merupakan model hidrologi yang banyak digunakan untuk mengevaluasi dampak perubahan iklim, penggunaan lahan, dan pengelolaan lahan terhadap karakteristik hidrologi (Arnold et al., 2011 dalam Mubarok, 2015).

SWAT dapat digunakan untuk menganalisis debit sungai pada suatu DAS. Penggunaan model SWAT terlebih dahulu perlu dilakukan kalibrasi sesuai dengan ketersediaan data, agar hasil yang 
diperoleh dapat sesuai dengan kondisi sebenarnya dilapangan. Proses ini dibutuhkan karena setiap DAS memiliki karakteristik yang berbeda-beda. Relevansi model dengan keadaan yang sebenarnya di evaluasi dengan menghitung koefesien determinasi dan efesiensi model (Rau, 2012). Penelitian ini bertujuan untuk menganalisis debit dan mengkaji kinerja model SWAT dalam mempresentasikan debit DAS Air Dingin.

\section{METODE PENELITIAN}

\section{A. Waktu dan Tempat}

Penelitian ini dilakukan di kawasan DAS Air Dingin Kota Padang. Pengolahan data dilakukan di Laboratorium Teknik Sumber Daya Lahan dan Air, Universitas Andalas Padang. Penelitian ini dilaksanakan mulai bulan Desember 2016 sampai dengan Februari 2017.

\section{B. Alat dan Bahan}

Alat yang digunakan dalam penelitian ini yaitu : Perangkat keras berupa seperangkat komputer. Perangkat lunak ArcGIS 10.3, ArcSWAT versi 2012.10.3.18, pcpSTAT, Er Mapper 7.1, SWAT Plot, SWAT-CUP, Database HWSD, SPAW Model dan Microsoft Office. Global Positioning System (GPS). Kamera digital dan alat penyimpanan data.

Bahan yang dibutuhkan dalam penelitian ini yaitu : Peta administrasi Kota Padang (RTRW Kota Padang tahun 2008-2018 Bappeda Kota Padang). Peta penggunaan lahan DAS Air Dingin. Peta dan data sifat fisik tanah (Database Harmonized World Woil Database/HWSD). Data Digital Elevation Mode (DEM) resolusi 30 x 30 meter (http://dds.cr.usgs.gov/). Data hidrologi berupa curah hujan stasiun Bendung Koto Tuo, Kasang, Gunung Nago dan debit Air Dingin tahun 2005-2015 (PSDA Sumatera Barat). Data iklim harian berupa temperatur maksimum, temperatur minimum, radiasi matahari, kelembaban udara, dan kecepatan angin tahun 2005-2014) (BMKG Stasiun Meteorologi Kelas II Minangkabau).

\section{Prosedur Penelitian}

1. Penyiapan data input

Data input yang dibutuhkan dalam model SWAT yaitu data tanah, penggunaan lahan, iklim dan DEM dipersiapkan dalam format database. Data iklim yang dikumpulkan merupakan data iklim harian yang meliputi data curah hujan, suhu maksimum dan minimum, radiasi matahari dan kelembaban relatif.

2. Prosedur Aplikasi SWAT

a. Deliniasi DAS (Watersheed Deliniator) dengan data input berupa data DEM. Daerah observasi akan dideliniasi berdasarkan batas topografi alami DAS. Metode yang digunakan dalam proses deliniasi adalah metode threshold yang akan menentukan jumlah jaringan sungai yang terbentuk.

b. Pembentukan HRU (Hydrologi Respont Unit Analysis) dengan data input peta penggunaan lahan, peta topografi, dan peta serta data sifat fisik tanah. HRU adalah satuan lahan dengan unsur karakteristik sub DAS yang berpengaruh terhadap terjadinya erosi. Setiap HRU akan memiliki informasi sub DAS, nomor HRU, jenis penutupan lahan, jenis tanah, dan luas HRU. HRU didapatkan dari overlay peta tanah dan peta penggunaan lahan.

c. Basis data iklim, dengan membuat data generator iklim (weather generator data) hasil perhitungan data curah hujan, suhu, radiasi matahari, kelembaban, dan kecepatan angin.

d. Penggabungan HRU dengan data iklim, proses ini dilakukan setelah analisis terbentuk. Pada tahap ini ditentukan periode simulasi terlebih dahulu untuk kemudian dilakukan pemasukan data iklim.

e. Simulasi SWAT, dilakukan dengan memilih waktu yang akan disimulasikan pada mode Run SWAT. Penyimpanan data output hasil simulasi dilakukan dengan memilih Read SWAT Output.

3. Kalibrasi Model SWAT

Kalibrasi adalah pengujian model agar dapat menggambarkan keadaan sebenarnya, perbandingan secara visual antara kurva debit (hidrograf) hasil simulasi dengan kurva debit hasil 
pengukuran stasiun pengamatan. Kalibrasi model SWAT dilakukan dengan membandingkan debit simulasi dengan hasil pengukuran debit di stasiun pengamatan. Kalibrasi dilakukan sampai hasil simulasi mendekati hasil pengukuran. Prosedur kerja kalibrasi mengikuti Neisch et al. (2004).

Metode statistik yang digunakan dalam melakukan kalibrasi adalah koefisien determinasi $\left(\mathrm{R}^{2}\right)$ dan efesiensi model (NS) Nash Sutcliffe (Abbaspour, 2015). Koefisien determinasi dihitung menggunakan persamaan:

$$
R^{2}=\left(\frac{\left[\sum_{i=1}^{n}\left(Q_{m, i}-\overline{Q_{m}}\right) \cdot\left(Q_{s, i}-\overline{Q_{s}}\right)\right]}{\sqrt{\sum_{i=1}^{n}\left(Q_{m, i}-\overline{Q_{m}}\right)^{2}} \cdot \sum_{i=1}^{n}\left(Q_{s, i}-\overline{Q_{s}}\right)^{2}}\right)^{2}
$$

Kisaran nilai $\mathrm{R}^{2}$ diantara 0 dan 1 menggambarkan seberapa banyak sebaran data observasi yang dapat dijelaskan oleh data simulasi. Pada dasarnya nilai $\mathrm{R}^{2} \geq 0.5$ dianggap dapat diterima (Moriasi $e t$ al. 2007), sehingga model yang dibuat dapat dipergunakan untuk mensimulasikan skenario yang diinginkan. Adapun efisiensi model (NS) Nash Sutcliffe dihitung menggunakan persamaan:

$$
N S=1-\frac{\sum_{i=1}^{n}\left(Q_{m, i}-\overline{Q_{s}}\right)^{2}}{\sum_{i=1}^{n}\left(Q_{m, i}-\overline{Q_{m}}\right)^{2}}
$$

Keterangan:

$Q m=$ Debit aktual rata-rata yang terukur (mm)

$Q s=$ Debit hasil simulasi rata-rata $(\mathrm{mm})$

$Q m, i=$ Debit aktual yang terukur $(\mathrm{mm})$

$Q s, i=$ Debit hasil simulasi $(\mathrm{mm})$

Kategori simulasi berdasarkan nilai NS adalah sebagai berikut :
a. Layak jika $>0.75$
b. Memuaskan jika $0.75>\mathrm{NS}>0.36$
c. Kurang memuaskan jika $<0.36$

\section{Analisis Data}

Analisis data dilakukan terhadap hasil kalibrasi data debit. Jika hasil kalibrasi didapatkan memuaskan atau layak maka model SWAT dapat diaplikasikan untuk berbagai kondisi dalam manajemen sumberdaya air di DAS Air Dingin. Model dianggap layak bila model tersebut dapat menggambarkan atau mendekati keadaan yang sebenarnya. Nilai kelayakan model dapat diukur dengan koefisien determinasi serta efisiensi model yang tinggi (Suryani dan Agus, 2005)

\section{HASIL DAN PEMBAHASAN}

\section{A. Gambaran Umum Daerah Penelitian}

Daerah aliran sungai (DAS) Air Dingin merupakan salah satu DAS yang terletak di Kecamatan Koto Tangah Kota Padang yang bermuara langsung ke lautan. Secara geografis terletak pada $0^{\circ} 45^{\prime}-$ $0^{\circ} 55^{\prime}$ Lintang Selatan dan $100^{\circ} 20^{\prime}-100^{\circ} 30^{\prime}$ Bujur Timur dan berada pada ketinggian 0 - 1808 mdpl, dengan luas 12477.32 ha. Topografi wilayah DAS Air dingin adalah datar, curam dan agak curam dengan kemiringan lahan $0-50 \%$. Batas-batas wilayah DAS Air dingin antara lain : sebelah utara berbatasan dengan DAS Batang Kandis, sebelah selatan berbatasan dengan Kuranji, sebelah barat berbatasan dengan Samudera Hindia, dan sebelah timur berbatasan dengan Kabupaten Solok seperti terlihat pada Gambar 1. 


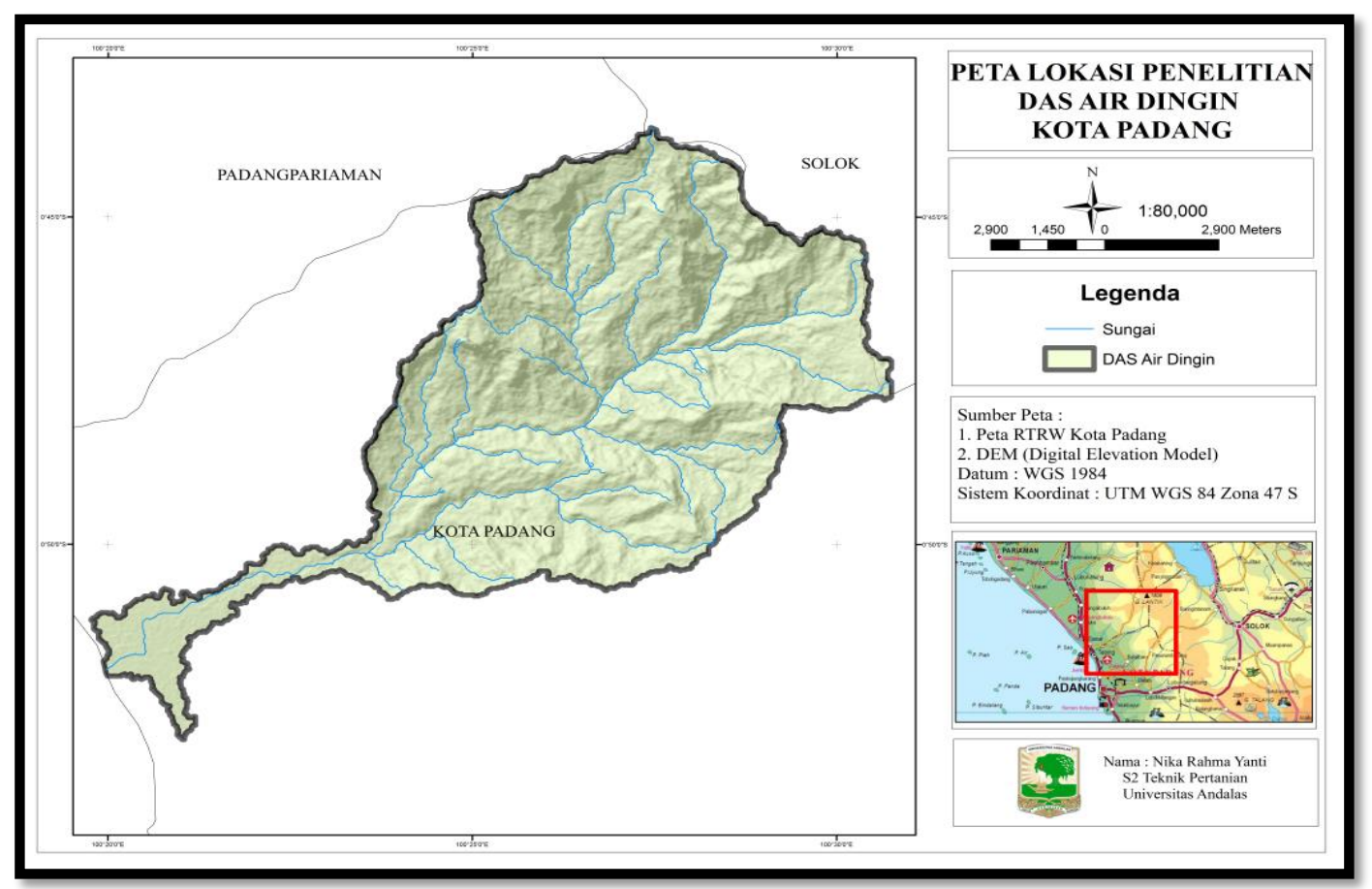

Gambar 1. Peta Lokasi Penelitian

1. Iklim

Data iklim daerah penelitian berupa data sekunder iklim berdasarkan rekaman data dari Stasiun Meteorologi Minangkabau BMKG dari tahun 2005 sampai 2015. Kondisi iklim pada DAS Air Dingin dapat dilihat pada Tabel 1.

Tabel 1. Kondisi iklim DAS Air Dingin

\begin{tabular}{lcccc}
\hline \multicolumn{1}{c}{ Bulan } & Suhu $\left({ }^{\circ} \mathrm{C}\right)$ & $\mathrm{RH}(\%)$ & K. Angin $(\mathrm{m} / \mathrm{s})$ & Radiasi $\left(\mathrm{MJ} / \mathrm{m}^{2}\right)$ \\
\hline Januari & 27,0 & 81,3 & 1,4 & 15,3 \\
Februari & 27,1 & 80,9 & 1,4 & 16,5 \\
Maret & 27,2 & 81,4 & 1,4 & 14,5 \\
April & 27,4 & 81,9 & 1,4 & 15,2 \\
Mai & 27,5 & 80,9 & 1,4 & 16,4 \\
Juni & 27,2 & 81,0 & 1,5 & 16,7 \\
Juli & 26,7 & 81,0 & 1,5 & 16,5 \\
Agustus & 26,8 & 82,1 & 1,5 & 16,4 \\
September & 26,6 & 82,9 & 1,5 & 14,9 \\
Oktober & 26,8 & 83,7 & 1,4 & 14,8 \\
November & 26,8 & 84,1 & 1,5 & 14,6 \\
Desember & 26,9 & 83,0 & 1,4 & 14,5 \\
\hline
\end{tabular}

Sumber: Hasil Analisis 2017

Berdasarkan Tabel 1 dapat dilihat bahwa RH atau kelembaban berkisar antara $80-84 \%$, ini dikarenakan stasiun pengukuran yang berada dekat dari pantai dan pada ketinggian 9 mdpl. Suhu ratarata $27^{\circ} \mathrm{C}$ dan kecepatan angin $1,4 \mathrm{~m} / \mathrm{s}$. Besar radiasi matahari berkisar antara $14,5-16,7 \mathrm{MJ} / \mathrm{m}^{2}$.

Curah hujan bulanan penelitian ini menggunakan 3 stasiun yaitu stasiun Minangkabau, Bendung Koto Tuo dan Kasang tahun 2005 - 2015. Seperti terlihat pada Gambar 2 hujan maksimum terjadi pada bulan November sebesar 526,09 mm seiring dengan $\mathrm{RH}$ yang terlihat pada Tabel $1 \mathrm{RH}$ 
maksimum terjadi pada bulan November sebesar $84,1 \%$. Hujan minimum terjadi pada bulan mei sebesar 236,82 mm dengan RH 80,9\%.

Menurut klasifikasi Oldeman, DAS Air dingin termasuk tipe zona ilklim A karena memiliki bulan basah yang merata setiap bulannya. Pembagian iklim menurut Oldeman berdasarkan pada bulan basah, bulan lembab dan bulan kering. Bulan basah terjadi curah hujan lebih dari $200 \mathrm{~mm}$, bulan lembab $100-200 \mathrm{~mm}$, dan bulan kering kecil dari $100 \mathrm{~mm}$ (Kartasapoetra, 2008).

Curah hujan merupakan faktor utama yang mengendalikan proses daur hidrologi suatu DAS. Terbentuknya ekologi, geografi dan tataguna lahan suatu daerah sebagian besar ditentukan atau tergantung pada fungsi daur hidrologi, dan dengan demikian, presipitasi merupakan Kendala sekaligus kesempatan dalam usaha pengelolaan sumberdaya tanah dan air (Asdak, 2010).

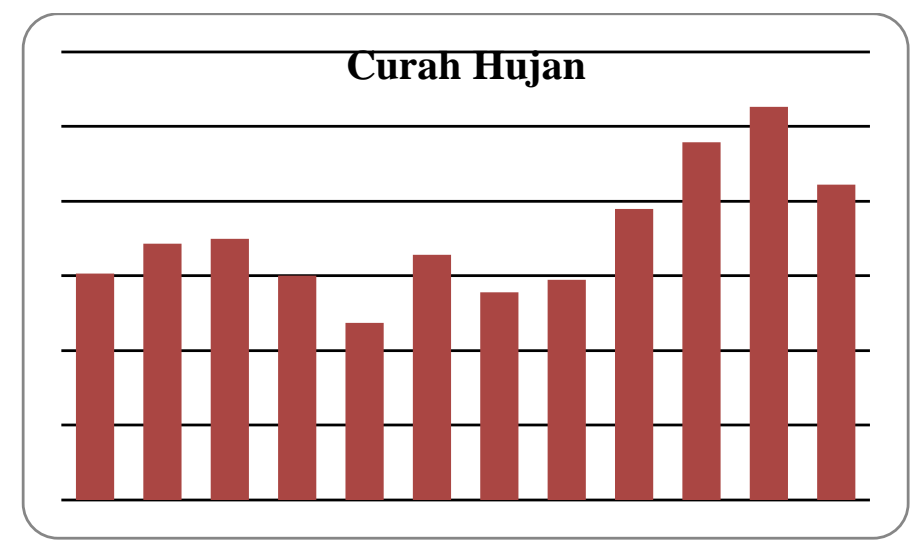

Gambar 2. Grafik Rata-Rata Curah Hujan Bulanan (2005-2015)

2. Kondisi Tanah

Karakteristik tanah DAS Air Dingin dikelompokan menjadi 2 jenis tanah berdasarkan FAO 1974, dari database HWSD (Harmonized World Soil Database). Klasifikasi tanah DAS air dingin dapat dilihat pada Tabel 2.

Tabel 2. Klasifikasi Tanah DAS Air Dingin

\begin{tabular}{lcc}
\hline \multicolumn{1}{c}{ Jenis Tanah } & Luas (Ha) & Persentase DAS (\%) \\
\hline Kambisol & 8380,38 & 67,16 \\
Andosol & 4096,93 & 32,84 \\
\hline Total & 12477 & 100 \\
\hline
\end{tabular}

Berdasarkan database HWSD terdapat 2 jenis tanah pada DAS Air Dingin yaitu Kambisol dan Andosol. Sistem klasifikasi tanah FAO atau lebih dikenal dengan satuan tanah FAO dibangun tahun 1974 dalam rangka penyusunan peta tanah dunia skala 1:5.000.000 oleh FAO/UNESCO (Subardja dkk, 2014). Database HWSD menyediakan data tekstur tanah berdasarkan persen pasir, liat dan lempung, karbon organik tanah, PH tanah. Data tanah akan dilengkapi dengan SPAW model dengan menginputkan data tekstur tanah, maka akan keluar output field capacity, saturation, available water, saturated hydraulic conductivity dan bulk density (Saxton dan wiley, 2001).

Jenis tanah sangat mempengaruhi besar atau kecilnya laju infiltrasi, dan aliran permukaan. Apabila tanah yang ada pada lahan padat maka laju infiltrsinya akan lambat karena partikel-partikel tanah sangat rapat sehingga pori-pori tanah akan tertutup dan akan mengakibatkan air akan sedikit masuk kedalam tanah dan memperbanyak aliran permukaan.

Menurut Darmawijaya (1990) dalam Arlius (2007) tanah Andosol mempunyai sifat fisik yang baik berupa daya pengikatan air yang sangat tinggi, dan jika ditutupi vegetasi selalu jenuh air dan sangat gembur. Pada DAS Air dingin tanah Andosol berada pada bagian hulu yang ditutupi oleh hutan seluas 4096,93 ha $(32,84 \%)$ dengan ini bagian hulu dapat menyerap air dengan besarnya infiltrasi dan 
memperkecil aliran permukaan. Sedangkan $67,16 \%$ DAS Air dingin memiliki jenis tanah Kambisol yang berada pada bagian tengah sampai hilir DAS.

\section{Kemiringan Lahan}

Faktor kemiringan lahan secara tidak langsung mempengaruhi besarnya debit yang keluar dari outlet. Daerah dengan kemiringan yang curam mengakibatkan air akan terakumulasi dan memiliki potensi runoff dan erosi pada saat terjadi hujan. Air yang berada pada lahan dengan kemiringan semakin curam akan diteruskan ketempat yang lebih rendah lebih cepat dibandingkan dengan lahan yang kemiringannya kecil (datar). Pemilihan penggunaan lahan serta pengelolaan lahan yang baik akan menurunkan tingkat kerusakan yang ditimbulkan. Data kemiringan DAS Air Dingin dibuat berdasarkan pengolahan DEM (digital elevation model). Kemiringan lahan DAS Air Dingin dibagi menjadi lima kelas yang dapat dilihat pada Tabel 3 .

Tabel 3. Kemiringan Lahan DAS Air dingin

\begin{tabular}{ccc}
\hline Kemiringan $(\%)$ & Luas (ha) & Persentasi DAS $(\%)$ \\
\hline $0-8$ & 932,48 & 7,47 \\
$8-15$ & 1052,9 & 8,44 \\
$15-25$ & 1978,5 & 15,86 \\
$25-45$ & 4353,37 & 34,89 \\
$>45$ & 4160,06 & 33,34 \\
\hline Total & 12477 & 100
\end{tabular}

Sumber: Hasil Analisis 2017

Berdasarkan Tabel 3 dapat dilihat kemiringan DAS Air Dingin yang landai hanya 7,47 \% yang didominasi oleh sawah dan pemukiman. Kemiringan yang sangat curam 33,34 \% dari total luas DAS. Paling banyak DAS Air dingin berada pada kemiringan 25 - $45 \%$ (curam) sekitar $34.89 \%$.

\section{Penggunaan Lahan}

Penggunaan lahan pada DAS Air Dingin telah mengalami perubahan yang cukup signifikan pada setiap tahunnya. Berdasarkan klasifikasi citra Landsat penggunaan lahan DAS Air Dingin tahun 2010 diperoleh data seperti pada tabel 4.

Tabel 4. Penggunaan Lahan DAS Air Dingin Tahun 2010

\begin{tabular}{lcc}
\hline Penggunaan Lahan & Luas Ha & $(\%)$ \\
\hline Hutan & 9930,72 & 79,59 \\
Pertanian Lahan Kering Bercampur & 2111,75 & 16,92 \\
Semak & 207,02 & 1,66 \\
Pemukiman & 142,79 & 1,14 \\
Sawah & 68,4 & 0,55 \\
Bandara & 16,62 & 0,13 \\
Badan Air & & \\
\hline
\end{tabular}

Sumber: Hasil Analisis 2017

Lahan yang ditanami oleh vegetasi akan mengurangi besarnya debit karena besarnya infiltrasi sehingga runoff menjadi kecil karena waktu perjalanan runoff menuju saluran lebih lama sebab tertahan oleh akar dan batang pohon. Apabila lahan bervegetasi terus menerus di buka untuk diganti penggunaan lahannya akan menyebabkan tangkapan air mengecil sehingga runoff menjadi besar dan air akan langsung menuju saluran utama. Pada tabel 4 dapat dilihat bahwa 79,59 \% lahan pada DAS Air Dingin adalah hutan dan hal ini hendaknya dapat memperkecil runoff yang terjadi. 
Menurut Asdak 2010, air hujan yang jatuh di atas permukaan vegetasi yang lebat, terutama pada permulaan hujan, tidak langsung mengalir ke permukaan tanah. Untuk sementara, air tersebut akan ditampung oleh tajuk, batang dan cabang vegetasi. Setelah tempat-tempat tersebut jenuh dengan air, maka air hujan yang datang kemudian akan menggantikan air hujan yang tertampung tersebut untuk selanjutnya menetes ke tajuk, batang dan cabang vegetasi di bawahnya sebelum akhirnya sampai di atas tumbuhan bawah, seresah dan permukaan tanah.

\section{B. Analisis SWAT}

SWAT merupakan perangkat lunak yang berguna dalam melakukan distribusi data, mengembangkan tools yang berkaitan dengan analisis spasial dan melakukan proses sebagaimana perangkat lunak GIS lainnya.

\section{Proses Deliniasi DAS}

Deliniasi DAS dilakukan berdasarkan data DEM (digital elevation Model) wilayah DAS Air Dingin dengan resolusi $30 \mathrm{~m}$. Proses deliniasi tersebut menghasilkan batas DAS, batas sub DAS, dan jaringan sungai. Berdasarkan proses deliniasi DAS Air Dingin terbentuk jaringan sungai utama, batas DAS dengan total luas 12477 ha, dan sub DAS sebanyak 11 seperti terlihat pada Gambar 3. Data debit pengukuran lapangan digunakan sebagai data primer dibandingkan dengan data debit simulasi dalam model SWAT.

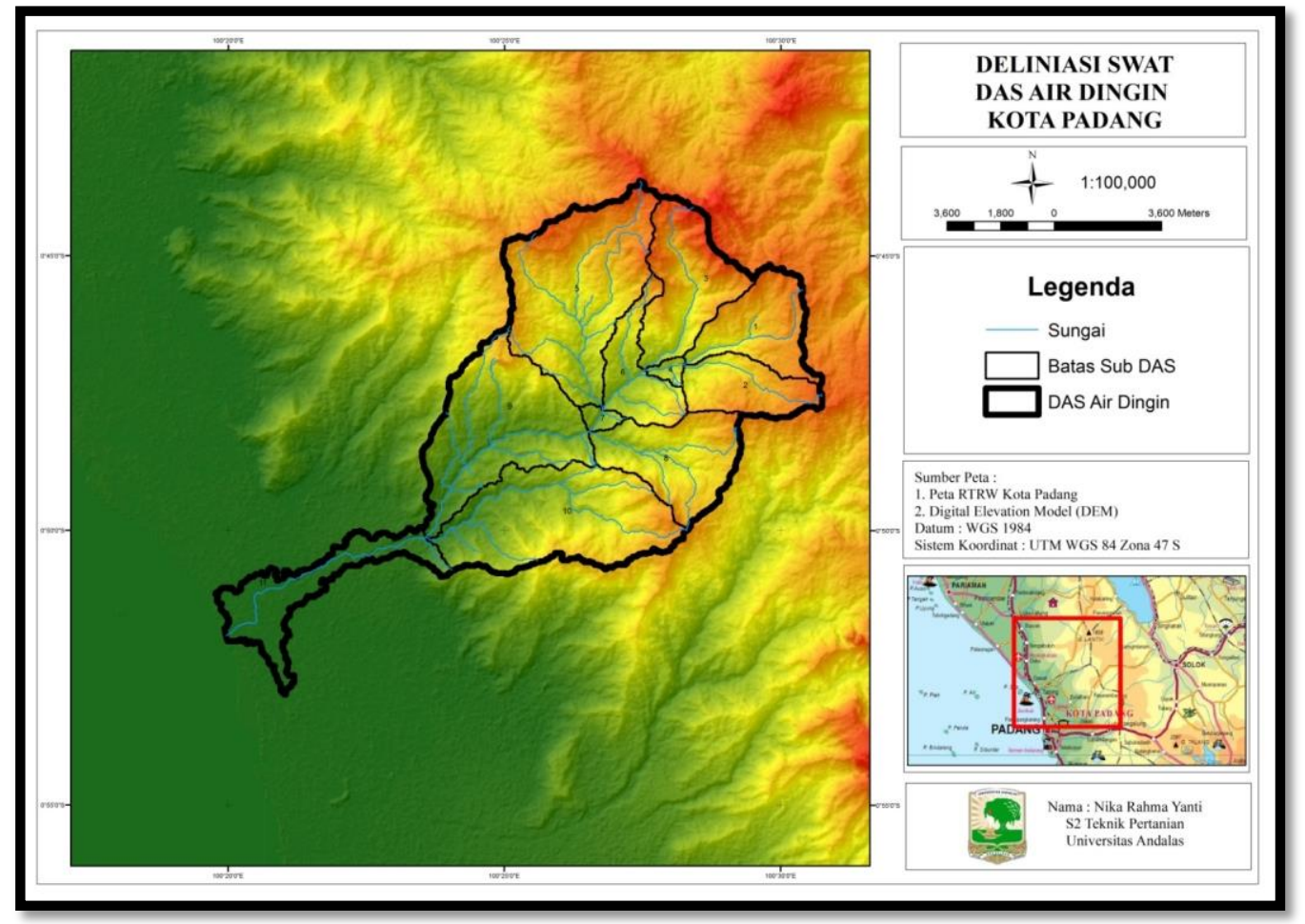

Gambar 3. Bentuk DAS Air Dingin Hasil Deliniasi SWAT

Berdasarkan Gambar 3 dapat dilihat bahwa DAS Air Dingin dibagi menjadi 11 sub DAS berdasarkan deliniasi SWAT. Luasan masing-masing sub DAS berbeda tergantung kepada bentuk morfologi sungai. Sub DAS terkecil yaitu sub DAS 4 dengan luasan $78,76 \mathrm{Ha}(0,63 \%)$ dan paling luas terdapat pada sub DAS 5 yaitu 2365,61 Ha (18,96\%). DAS Air Dingin berada pada ketinggian 0 1808 mdpl dan bermuara langsung ke Samudra Hindia.

\section{Pembentukan HRU}

Unit lahan yang terbentuk oleh model SWAT yang merupakan tumpang tindih (overlay) dari jenis tanah, penggunaan lahan dan kemiringan lereng yang terdapat pada DAS Air Dingin disebut HRU. 
HRU yang terbentuk oleh model dengan menggunakan metode threshold by persentage (dimana untuk jenis tanah menggunakan threshold $10 \%$, jenis tanah menggunakan threshold $5 \%$ dan kemiringan lereng menggunakan threshold $5 \%$ ) sejumlah 73 HRU. HRU yang terbentuk oleh model untuk masingmasing sub DAS pada DAS Air Dingin. Hasil pembentukan HRU memberikan informasi mengenai penggunaan lahan, tanah, kemiringan lahan, luas area dan persentase dari dari DAS.

\section{Pengolahan Data dan Simulasi SWAT}

Input data iklim untuk mendapatkan keluaran debit hasil simulasi. Simulasi SWAT membutuhkan data iklim berupa curah hujan dan suhu pada stasiun yang mewakili atau yang terdekat dari DAS Air dingin, serta data weather generator berupa radiasi matahari, kecepatan angin suhu, curah hujan dan kelembaban. Data weather generator yang digunakan pada proses simulasi yaitu dari stasiun meteorologi Minangkabau tahun 2005 - 2015 yang terletak pada $00^{\circ} 47^{\prime} 18^{\prime \prime}$ LS dan 100 16' 51" BT dengan elevasi 9 meter diatas permukaan laut. Data weather generator memberikan informasi mengenai temperatur maksimum dan minimum rata-rata bulanan, nilai standar deviasi untuk temperatur maksimum dan minimum, nilai curah hujan rata-rata, nilai standar deviasi curah hujan, nilai kemencengan curah hujan, nilai probabilitas hari kering terhadap hari hujan dan hari hujan terhadap hari hujan, jumlah hari hujan, nilai curah hujan maksimum, radiasi matahari, dan kecepatan angin.

\section{Visualisasi}

Visualisasi debit dilakukan untuk menggambarkan keadaan debit hasil simulasi dengan debit observasi DAS Air Dingin seperti yang dapat dilihat pada Gambar 4. Berdasarkan visualisasi yang diperoleh, debit simulasi maksimum yaitu $31,4 \mathrm{~m}^{3} / \mathrm{s}$, debit simulasi minimum $2,715 \mathrm{~m}^{3} / \mathrm{s}$ dan debit simulasi rata-rata $13,74 \mathrm{~m}^{3} / \mathrm{s}$. Debit observasi lapangan maksimum yaitu $28,8 \mathrm{~m}^{3} / \mathrm{s}$, debit observasi lapangan minimum yaitu $3,64 \mathrm{~m}^{3} / \mathrm{s}$, dan debit obervasi rata-rata $11,77 \mathrm{~m}^{3} / \mathrm{s}$.

Berdasarkan data ini tampak perbedaan antara debit simulasi dengan debit observasi, terlihat bahwa debit simulasi memiliki nilai lebih tinggi dari debit observasi. Seperti terlihat pada Gambar 5 korelasi antara debit observasi dengan debit simulasi diperoleh $\mathrm{R}^{2}$ sebesar 0,53 . Hal ini dikarenakan lokasi pengukuran debit tidak berada pada outlet DAS Air Dingin, yakni agak ketengah bagian DAS. Data debit observasi diperoleh dari pos pengukuran AWLR DAS Air Dingin, Kecamatan Koto Tangah pada tahun 2009 - 2014, dimana lokasi pengukuran debit berada pada $0^{\circ} 50^{\prime} 19,3^{\prime \prime}$ LS dan $100^{\circ} 22^{\prime}$ 49,2" BT.

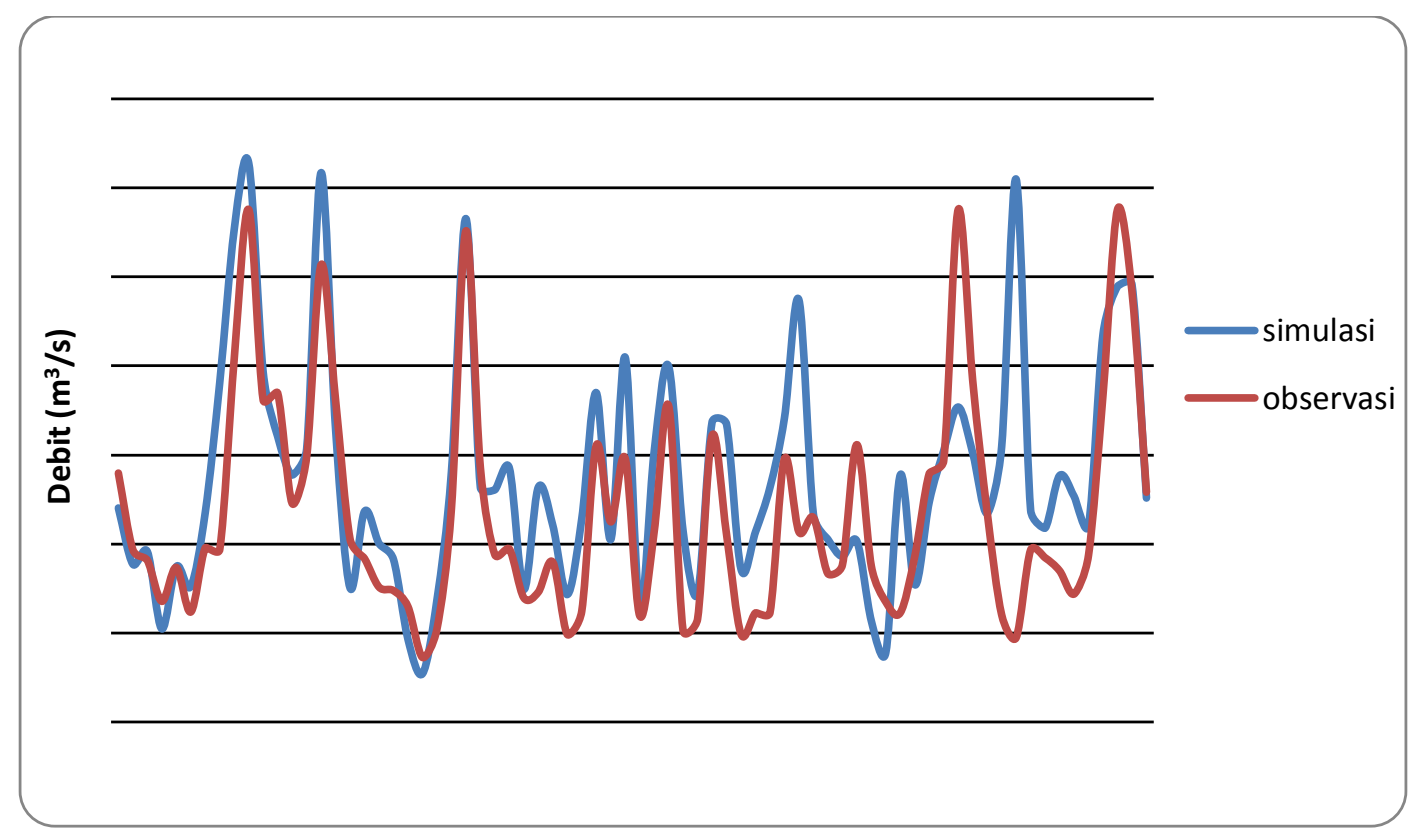

Gambar 4. Fluktuasi Debit Hasil Simulasi dengan Observasi 


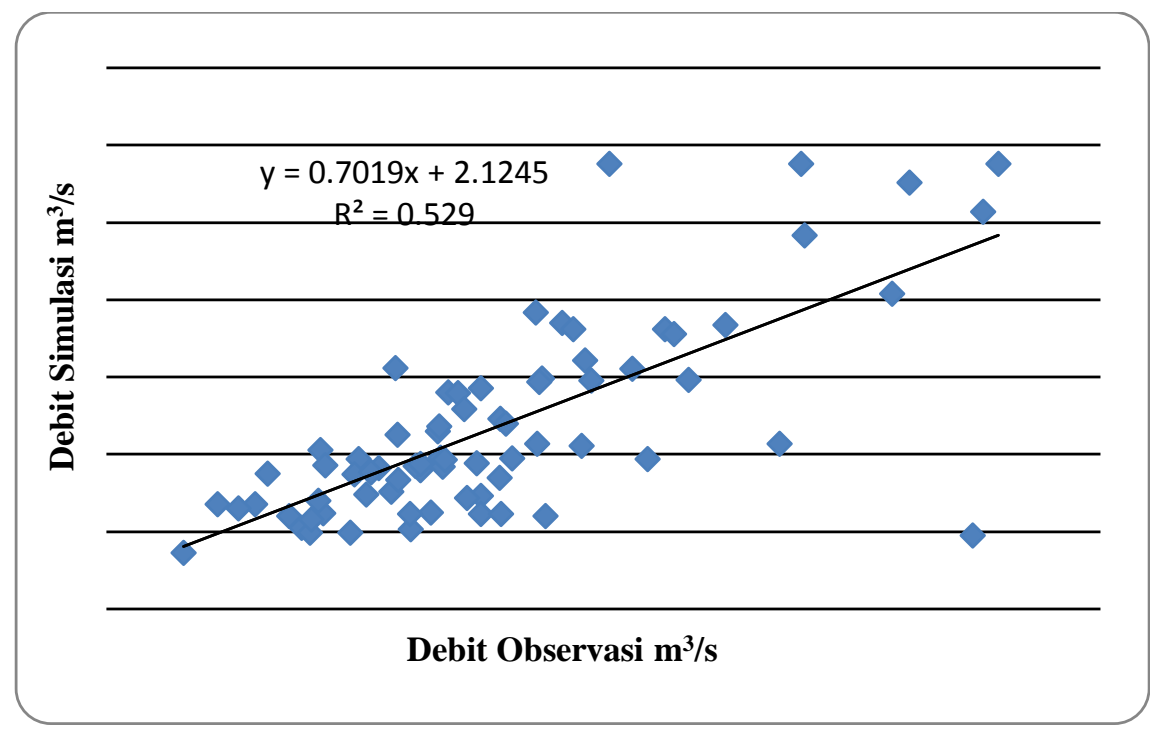

Gambar 5. Grafik Korelasi Debit Simulasi dengan Observasi

\section{Kalibrasi Model SWAT}

Hasil debit simulasi SWAT kurang menggambarkan keadaan di lapangan berdasarkan data observasi, perbedaan ini disebabkan data yang kurang mendekati keadaan sebenarnya. Hal ini dapat diperbaiki dengan melakukan kalibrasi agar hasil simulasi dapat digunakan ke tahun-tahun berikutnya. Kalibrasi model SWAT yang dilakukan pada penelitian ini menggunakan SWAT-CUP dengan metode SUFI-2 (sequential uncertainty fitting). Kalibrasi dilakukan dengan membandingkan debit observasi dengan debit simulasi model SWAT. Kalibrasi dengan SWAT-CUP dilakukan berdasarkan range nilai minimum dan maksimum. Pada awal proses, dapat dilakukan pemasukan data berdasarkan file_absolute_SWAT_Values.txt. File tersebut berguna dalam mengetahui range nilai awal yang dianjurkan. Setelah tahap iterasi pertama dilakukan, diperoleh range nilai baru yang disarankan pada new_pars.txt, yang dapat dimasukkan kembali kedalam parameter. Hal ini kemudian dilakukan secara berulang hingga diperoleh nilai yang diinginkan (Rau, 2012).

Debit aliran adalah laju aliran air dalam bentuk volume yang melewati suatu penampang melintang sungai per satuan waktu. Aliran sungai berasal dari hujan yang masuk ke dalam sungai dalam bentuk aliran permukaan, aliran bawah permukaan, air bawah tanah, dan butir-butir hujan yang langsung jatuh dipermukaan sungai. Debit sungai akan naik setelah terjadi hujan yang cukup, kemudian akan kembali setelah hujan selesai (Arsyad, 2010). Model SWAT merupakan model komprehensif yang mensimulasikan interaksi antar parameter. Sebagai contoh, nilai CN secara langsung mempengaruhi aliran permukaan. Ketika aliran permukaan berubah, maka komponen hidrologi lainnya juga akan berubah (Sulaeman, 2016). Kalibrasi pada penelitian ini dilakukan sebanyak 20 kali iterasi dengan 100 simulasi pada tiap iterasinya. Parameter dan masukan nilai akhir dapat dilihat pada Tabel 5.

Berdasarkan Tabel 5 diatas dapat dilihat bahwa terdapat 15 parameter yang perlu diubah dalam menganalisis debit DAS Air Dingin. Parameter yang paling berpengaruh adalah faktor pengisian air tanah GW_Delay yakni 18,6 hari sedangkan nilai sebelum kalibrasi adalah 240 hari. Parameterparameter ini merupakan parameter yang harus diganti untuk menjalankan SWAT dalam melakukan simulasi agar hasil simulasi mendekati kondisi lapangan.

Setelah dilakukan kalibrasi akan didapatkan debit simulasi yang mendekati keadaan sebenarnya (debit observasi). Seperti terlihat pada Gambar 6 grafik hubungan debit simulasi dengan observasi setelah dilakukan kalibrasi. Diperoleh korelasi $\mathrm{R}^{2}$ sebesar 0,757 dengan persamaan $\mathrm{y}=0,810 \mathrm{x}+0,891$. 


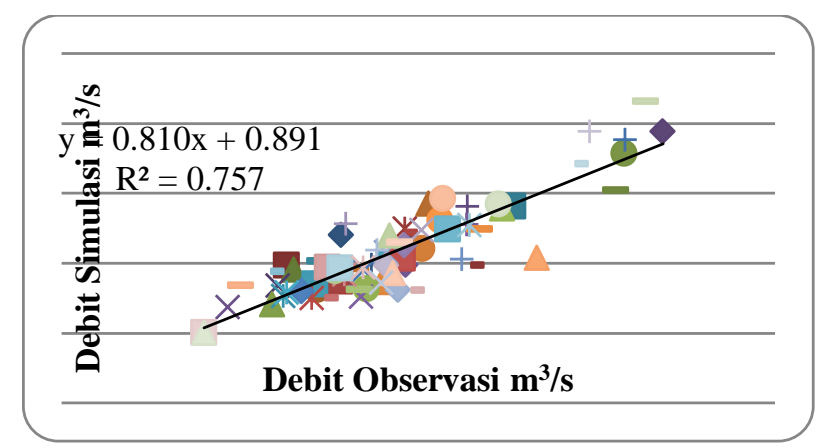

Gambar 6. Grafik Hasil Kalibrasi Debit DAS Air Dingin

Tabel 5. Parameter dan Masukan Nilai yang digunakan pada Kalibrasi

\begin{tabular}{llc}
\hline Parameter & Defenisi (satuan) & $\begin{array}{c}\text { Nilai } \\
\text { Masukan }\end{array}$ \\
\hline R_CN2.mgt & SCS curve number & 0,053 \\
V_ALPHA_BF.gw & Faktor alfa untuk aliran permukaan (hari) & 0,154 \\
V_GW_DELAY.gw & Waktu pengisian air tanah (hari) & 18,602 \\
R_GW_REVAP.gw & Koefisien penguapan air tanah & 0,032 \\
R_REVAPMN.gw & Kedalaman ambang air pada akuifer dangkal agar perkolasi & 141,76 \\
R_ESCO.hru & mencapai akuifer dalam (mm) & 0,382 \\
R_EPCO.hru & Faktor pergantian evaporasi tanah & $-0,055$ \\
R_SLSUBBSN.hru & Paktor pergantian terusan tanaman & 61,61 \\
R_ALPHA_BNK.rte & Faktor alfa untuk aliran permukaan pada tampungan pinggir & 2,22 \\
R_SOL_BD(..).sol & sungai (hari) & Bulk density pada lapisan tanah (g/cm ${ }^{3}$ ) \\
R_OV_N.hru & Koefisien kekasaran manning & 0,73 \\
R_RCHRG_DP.gw & Fraksi perkolasi air tanah & 0,506 \\
R_CH_K2.rte & Konduktifitas hidrolik pada saluran utama & 0,45 \\
R_CH_N2.rte & Nilai manning dasar sungai & 40,92 \\
R_SURLAG.bsn & Lama limpasan permukaan (hari) & 13,72 \\
Sumber: Hasil Analisis 2017 &
\end{tabular}

Berdasarkan nilai statistik Tabel 6, bahwa $p$-factor yang diperoleh 0,83 sehingga model hasil kalibrasi belum sepenuhnya dikatakan baik namun mendekati. Nilai $\mathrm{R}^{2}$ dan NS tidak mencapai nilai seharusnya, sehingga kalibrasi masih kurang baik. $\mathrm{R}^{2}$ merupakan index yang mengukur kebaikan suai atau tidaknya persamaan regresi. Pada penelitian ini sebaran yang terjadi antara data debit simulasi dan observasi pada periode waktu tertentu tidak seragam.

Tabel 6. Nilai Statistik Hasil Penelitian menggunakan SWAT-CUP

\begin{tabular}{ccc}
\hline Variabel & Simulasi & Kalibrasi \\
\hline$p$-factor & - & 0,83 \\
$r$-factor & - & 1,22 \\
$\mathrm{R}^{2}$ & 0.53 & 0,76 \\
$\mathrm{NS}$ & 0.37 & 0,64 \\
\hline
\end{tabular}

Sumber: Hasil Analisis 2017 
Nilai $R^{2}$ berpengaruh langsung terhadap NS sehingga nilai NS yang diperoleh adalah 0,64 dengan $\mathrm{R}^{2}$ 0,76. Berdasarkan efisiensi model simulasi SWAT DAS Air Dingin dikatakan memuaskan dan model SWAT dapat digunakan pada DAS Air Dingin.

\section{KESIMPULAN}

Model SWAT dapat digunakan dalam mempresentasikan DAS Air Dingin. Hasil kalibrasi diperoleh nilai $\mathrm{R}^{2}$ sebesar 0,76 dan NS sebesar 0,64, simulasi SWAT yang dijalankan dikategorikan memuaskan. Besaran debit observasi sebanding dengan debit simulasi yaitu berkisar antara $3-30 \mathrm{~m}^{3} / \mathrm{s} . \mathrm{s}$

\section{DAFTAR PUSTAKA}

Arlius F. 2007. Analisis Spatio-Temporal Tutupan Lahan dan Neraca Air di Sub DAS CisangkuyCitarum hulu, Jawa Barat [Disertasi]. Bandung (ID): Universitas Padjajaran.

Arsyad S. 2010. Konservasi Tanah \& Air. Bogor (ID): IPB Press.

Asdak C. 2010. Hidrologi dan Pengelolaan Daerah Aliran Sungai. Yogyakarta (ID): UGM Press.

BPS. Badan Pusat Statisik. 2016. Padang Dalam Angka 2015. Padang.

Kartasapoetra. 2008. Klimatologi Pengaruh Iklim terhadap Tanah dan Tanaman. Jakarta (ID): Sinar Grafika.

Kodoatie RJ, Sjarief R. 2008. Pengelolaan Sumber Daya Air Terpadu. Yogyakarta (ID): Penerbit Andi. Mubarok Z. 2015. Kajian Respons Perubahan Penggunaan Lahan terhadap Karakterisik Hidrologi Das Way Betung Lampung. Jurnal Penelitian Kehutanan Wallacea Vol. 4 No.1, April 2015: 1-10.

Rau, I M. 2012. Analisi Debit Sungai dengan Menggunakan Model SWAT pada DAS Cipasauran, Banten [skripsi]. Bogor (ID): Institut Pertanian Bogor.

Subardja DS, Ritung S, Anda M, Sukarman, Suryani E, Subandiono RE. 2014. Petunjuk Teknis Klasifikasi Tanah Nasional. Bogor (ID): Badan penelitian dan pengembangan pertanian kementrian pertanian.

Sulaeman D. 2016. Simulasi Teknik Konservasi Tanah dan Air Metode Vegetatif dan Sipil Teknis Menggunakan Model Swat [tesis]. Bogor (ID): Institut Pertanian Bogor. 